\title{
Bioactive marine metabolites derived from The Persian Gulf compared to The Red Sea: similar environments and wide gap in drug discovery
}

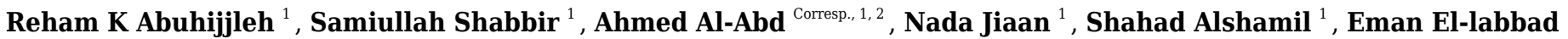
${ }^{1,3}$, Sherief Khalifa ${ }^{1}$

${ }^{1}$ Department of Pharmaceutical Sciences, College of Pharmacy, Gulf Medical University, Ajman, UAE, United Arab Emirates

2 Pharmacology Department, Medical Division, National Research Centre, Giza, Cairo, Egypt

3 Pharmaceutical Chemistry Department, Faculty of Pharmacy, Ain Shams University, Cairo, Egypt

Corresponding Author: Ahmed Al-Abd

Email address: ahmedmalabd@pharma.asu.edu.eg

Marine life has provided mankind with unique and extraordinary chemical structures and scaffolds with potent biological activities. Many organisms and secondary metabolites derived from fungi and symbionts are found to be more environmentally friendly to study than the marine corals per se. Marine symbionts such as Aspergillus sp., a fungus, which can be isolated and grown in the lab would be a potential and continuous source of bioactive natural compounds without affecting the marine environment. The Red Sea is known for its biodiversity and is well-studied in terms of its marine-derived bioactive metabolites. The harsh environmental conditions lead to the development of unique metabolic pathways. This, in turn, results in enhanced synthesis and release of toxic and bioactive chemicals. Interestingly, the Persian Gulf and the Gulf of Oman carry a variety of environmental stresses some of which are similar to the Red Sea. When compared to the Red Sea, The Persian Gulf has been shown to be rich in marine fungi as well, and is, therefore, expected to contain elaborate and interesting bioactive compounds. Such compounds may or may not be similar to the ones isolated from the Red Sea environment. Astoundingly, there are a very limited number of studies on the bioactive portfolio of marine-derived metabolites from the Persian Gulf and the Gulf of Oman. In this perspective, we are looking at the Red Sea as a comparator marine environment and bioactive materials repertoire to provide a futuristic perspective on the potential of the understudied and possibly overlooked bioactive metabolites derived from the marine life of the Persian Gulf and the Gulf of Oman despite its proven biodiversity and harsher environmental stress. 


\section{Bioactive marine metabolites derived from The}

3 Persian Gulf compared to The Red Sea: similar

4 environments and wide gap in drug discovery

5

6

7 Reham K. Abuhijjleh ${ }^{1}$, Samiullah Shabbir ${ }^{1}$, Ahmed M. Al-Abd ${ }^{1,2^{*}}$, Nada H. Jiaan ${ }^{1}$, Shahad

8 Alshamil $^{1}$, Eman M. El-labbad ${ }^{1,3}$, Sherief I. Khalifa ${ }^{1}$

9

10

11

${ }^{1}$ Department of Pharmaceutical Sciences, College of Pharmacy, Gulf Medical University, Ajman, United Arab Emirates.

2 Pharmacology Department, Medical Division, National Research Centre, Giza, Egypt.

${ }^{3}$ Pharmaceutical Chemistry Department, Faculty of Pharmacy, Ain Shams University, Abbassia 11566, Cairo, Egypt.

Corresponding Author:

Ahmed M. Al-Abd

Department of Pharmaceutical Sciences, College of Pharmacy, Gulf Medical University, P.O. 4184, Al-Jurf, Ajman, United Arab Emirates

Email address: ahmedmalabd@pharma.asu.edu.eg 


\section{Abstract}

24 Marine life has provided mankind with unique and extraordinary chemical structures and

25 scaffolds with potent biological activities. Many organisms and secondary metabolites derived from fungi and symbionts are found to be more environment friendly to study than the marine corals per se. Marine symbionts such as Aspergillus sp., a fungus, which can be isolated and grown in the lab would be a potential and continuous source of bioactive natural compounds without affecting the marine environment. The Red Sea is known for its biodiversity and is wellstudied in terms of its marine derived bioactive metabolites. The harsh environmental conditions lead to the development of unique metabolic pathways. This in turn, results in enhanced synthesis and release of toxic and bioactive chemicals. Interestingly, the Persian Gulf and Gulf of Oman carry a variety of environmental stresses some of which are similar to the Red Sea. When compared to the Red Sea, The Persian Gulf has been shown to be rich in marine fungi as well, and is therefore, expected to contain elaborate and interesting bioactive compounds. Such compounds may or may not be similar to the ones isolated from the Red Sea environment. Astoundingly; there are a very limited number of studies on the bioactive portfolio of marine derived metabolites from the Persian Gulf and the Gulf of Oman. In this perspective, we are looking at the Red Sea as a comparator marine environment and bioactive materials repertoire to provide a futuristic perspective on the potential of the understudied and possibly overlooked bioactive metabolites derived from the marine life of the Persian Gulf and Gulf of Oman despite its proven biodiversity and harsher environmental stress.

\section{Introduction}

Over the past couple of decades, the number of totally synthetic FDA approved drugs is significantly decreasing (Patridge et al., 2016). Yet, naturally occurring compounds with unique and new scaffold characteristics constitute a virgin area of drug discovery and an inspiring space for semisynthetic and synthetic drug discovery research. In the duration $1980-2010,26 \%$ of the newly approved drugs (1355 drugs) were natural products or natural compounds' derivatives (Newman \& Cragg, 2012). Terrestrial plant-derived natural products have a long history in supplying mankind with a giant library of unique stereo-chemically complex compounds with diverse biological activities. On the other hand, marine life provided drug discovery researchers with several unique and extraordinary chemical structures and scaffolds with very potent biological activities. Marine invertebrates (animals, vascular plants, algae, cyanobacteria, fungi and actinomycetes) produce these unique and potent biologically active metabolites as a result of evolutional pressure in the form of predation, space and resources' competition. The majority of these marine bioactive metabolites are of unique chemical structure and not reported in any terrestrial origin. It can be hypothesized that the more stressful the marine environment, the more unique and diverse metabolites are expected in marine organism (Seibel \& Drazen, 2007). The Red Sea is only second to the great barrier reef in Australia in terms of the biodiversity of its fauna with versatile bioactive metabolites repertoire. 


\section{Rationale:}

64 In the recent couple of decades, intensive drug discovery research shed the light on the Red Sea

65

66

67

68

69

70

71

72

73

74

75

76

77

78

79

80

81

82

83

84

85

86

87

88

89

90

91

92

93

94

95

96

97

98

99

100

101 marine invertebrates and its bioactive compositions. Several bioactive metabolites with unique chemical scaffolds were isolated, identified and showed promising pharmacological activities from the Red Sea marine life (El-Hossary et al., 2020). Biological activity herein is referred to in case of on any early experimental to late clinical evidence for potential use in the treatment of any human disease. On the other hand, the Persian Gulf and Gulf of Oman which are geographically close, atmospherically similar and under harsher environmental stress than the Red Sea, are surprisingly understudied in terms of bioactivity and drug discovery.

\section{Relevance to readers:}

Herein we are utilizing the Red Sea as a benchmark marine environment and bioactive materials repertoire to provide a futuristic perspective for the high potential of the understudied and overlooked bioactive metabolites derived from the marine life of the Persian Gulf and Gulf of Oman despite its rich biodiversity under harsh environmental stress. This review would be of special interest for researcher interested in drug discovery and in particular, those who are interested in marine derived bioactive metabolites.

\section{Survey methodology}

\section{Search strategy:}

The search for all relevant studies published was conducted on PubMed and Google Scholar, with the search terms being "Marine metabolites; Bioactive metabolites; Marine bioactive metabolites; Drug discovery; Secondary metabolites; The Red Sea; The Persian Gulf; The Arabian Gulf; Gulf of Oman; Fauna; Aspergillus sp.". Titles and abstracts were screened superficially for potential relevance, and once articles were deemed relevant, their full-texts were extracted and independently reviewed in depth to be considered for inclusion by the authors.

\section{Inclusion criteria:}

Only Scopus-indexed journals were considered up to the year 2000. Eligible study designs included review articles, systematic reviews and meta-analyses. English was the sole publication language considered. Editorials, pre-prints that were not peer-reviewed, case reports, database reports were excluded. 


\section{Environmental stress in the Persian Gulf and Gulf of Oman compared to the Red Sea}

107

108

109

110

111

112

113

114

115

116

117

118

119

120

121

122

123

124

125

126

127

128

129

130

131

132

133

134

135

136

137

138

139

140
The Persian Gulf/Gulf of Oman is a semi-enclosed sea, located in a subtropical region of the Middle East between latitudes of $24^{\circ}$ and $30^{\circ}$ North and longitudes $48^{\circ}$ and $57^{\circ}$ East. It is part of the Indo-Pacific Ocean ecoregion and consists of a shallow sedimentary basin with a relative depth of 35 meters and covering a total area of $240,000 \mathrm{~km}^{2}$. The maximum depth of the Persian Gulf/Gulf of Oman is approximately 110 meters and its photic zone extends between 6 to 15 meters. The Iranian shores have steep sloping sections while the Persian shores are sedimentary with a gradual slope. Considering the combination of high latitudinal position, high evaporation rates, relative shallowness, coastline alterations, heavy traffic volume, frequent oil spills, excessive industrial effluents and restricted freshwater flow into the Gulf; the Persian Gulf/Gulf of Oman is subject to extreme environmental conditions. Therefore, marine organisms residing in the Persian Gulf/Gulf of Oman are surviving close to their environmental tolerance limits (Naser, 2014).

With respect to the Red Sea, it is also a semi-enclosed sea, between latitudes of $22^{\circ}$ North and longitudes $38^{\circ}$ East. It covers an area of approximately $438,000 \mathrm{~km} 2$ and is connected from its south end via the strait of Bab el Mandeb and Gulf of Aden to the Indian Ocean. The Red sea is known for its coastal fringing coral reefs and its clear and warm water. The central trough reaches over 2,000 meters in the northern and central regions of the Red Sea. The sea bed rises from this trough to reach a depth of less than 300 to 400 meters (Ellis et al., 2019). The water temperature of the Persian Gulf fluctuates between $15^{\circ} \mathrm{C}$ to $36^{\circ} \mathrm{C}$ and the maximum recorded sea-surface temperatures was $38^{\circ} \mathrm{C}$ in the summer of 1998 (Paparella et al., 2019). Whereas, the Red sea surface temperatures ranges from $18^{\circ} \mathrm{C}$ to $31.5^{\circ} \mathrm{C}$. The temperature is lowest within the Gulf of Suez and increases gradually towards the southern half of the Red Sea (Gladstone, Facey \& Hariri, 2006; Hariri, Gladstone \& Facey, 2014).

The ecosystem in the Persian Gulf/Gulf of Oman is highly adapted to extreme environmental conditions but recent works have shown that it is not the maximum temperatures but rather the length of exposure that harms the marine life (Paparella et al., 2019). The reports demonstrated that mild bleaching occurs after a week of exposure to a sea-surface temperature of $>35^{\circ} \mathrm{C}$ and severe bleaching would occur after three weeks of exposure to temperatures $\geq 35^{\circ} \mathrm{C}$ or even $\geq 34^{\circ} \mathrm{C}$ exposure for eight weeks. Therefore, it is observed that the average temperature-related stress in the Persian Gulf/Gulf of Oman is higher than in the Red Sea.

The Persian Gulf receives its freshwaters from Shatt al Arab waterway through three different rivers: Euphrates, Tigris and Karun. Although, recent damn constructions have resulted in significant reduction of freshwater entering the Persian Gulf through these rivers, together with waters from Hilleh, Mand and Hendijan rivers in Iran, the annual input of freshwater into the

Peer) reviewing PDF | (2021:02:58376:1:1:NEW 14 Jun 2021) 
141 Gulf averages $110 \mathrm{~km}^{3}$ per year. On the other hand, the annual evaporation rates in the Persian

142 Gulf ranges between 1.37 to 4.8 meters. As a result, the marine system of Persian Gulf possesses

143 high salinity $>40 \mathrm{ppt}$, increasing to $>50 \mathrm{ppt}$ in the southern bays of open ocean conditions and

144 exceeding 70 ppt in evaporative lagoons (Ben-Hasan \& Christensen, 2019). Similarly, the

145 evaporation rate in the Red sea reaches 1 to 2 meters per year during both summer and winter.

146 The Gulf of Aqaba experiences evaporation rate of 2 meters per year and 2.35 meters per year in

147 the southern Red sea. As a result, the water salinity increases during summers reaching 37 ppt at

148 Bab el Mandeb and 41ppt towards the entrance of Gulf of Suez and Aqaba (Gladstone, Facey \&

149 Hariri, 2006; Hariri, Gladstone \& Facey, 2014). The combined limited freshwater input with

150 high evaporation rate makes the Red sea and similarly the Persian Gulf/Gulf of Oman to be the

151 most saline water in direct contact with the world oceans (Naser, 2014; Ben-Hasan \&

152 Christensen, 2019).

153 The Persian Gulf and Gulf of Oman are known for their high shipping traffic either oil and gas

154 import or foods and materials export. The high volume of shipping traffic and the sediments

155 curbed within these ships ballast tank has resulted in the introduction of various exotic biotas to

156 the marine system of the Persian Gulf/Gulf of Oman. The oil transportation alone accounts for

15753,000 ships passing through the Hormuz corridor into the Persian Gulf annually. To a lesser

158 extent, the Red sea is navigated by some of the most prominent shipping lanes in the world. It is

159 estimated that over 20,000 ships (oil and non-oil products) crosses through Bab el Mandeb strait

160 annually (Sheppard, 2018). It was reported that several exotic zooplankton and phytoplankton

161 organisms were collected from a ships ballast tank passing through the Persian Gulf (Al Muftah

162 et al., 2016). It can be concluded that shipping traffic and its consequent marine life stress in the

163 Persian Gulf significantly overweighs the Red sea.

164 The Persian Gulf is reported to have the largest oil reserves in the world and subsequently, oil

165 spills and pollution in water constitutes a permanent stress and survival challenge to its marine

166 life. The exploration, production and transportation of oil adds to the pollution in the Persian

167 Gulf. Various sources of oil spills were reported in the Persian Gulf such as oil tanker incidents,

168 offshore oil wells, weathered oil and tar balls, underwater pipelines, oil terminals, illegal ballast

169 water dumping and military activities (Naser, 2014). The Persian Gulf/Gulf of Oman has

170 witnessed several oil spill incidents in the near history, particularly in years 1980, 1990, 1991

171 and 2019. (Sale et al., 2011; Issa \& Vempatti, 2018; Eidnes, Batalden \& Sydnes, 2019). On the

172 other hand, the Regional Organization for the Conservation of the Environment of the Red Sea

173 and Gulf of Aden (PERSGA) prepared a partial report on Maritime incidents and accidents but

174 did not provide any accurate record of spills. So far, there has been no report of a major oil spill

175 or chemical pollution due to shipping incidents in the Red sea (Gladstone, Facey \& Hariri, 2006).

176 Yet, the number and the impact of oil spill incidents in the Persian Gulf/Gulf of Oman are way

177 higher compared to the Red sea.

178 In addition to oil spills, the Persian Gulf is considered a hotspot for receiving intensive industrial

179 effluents with high concentrations of hydrocarbons and heavy metals (Naser, 2014). The

180 pollutants reside in the Persian Gulf for a considerable amount of time due to its relatively slow 
181 flushing time (between 3 to 5 years) and semi-enclosed nature. The organic pollutants from the

182

183

184

185

186

187

188

189

190

191

192

193

194

195

196

197

198

199

200

201

202

203

204

205

206

207

208

209

210

211

212

213

214

215

216

217

218

219

agricultural runoffs enter the Persian Gulf through the rivers causing lower oxygen levels in coastal waters (Sale et al., 2011). Similarly, and due to the semi-enclosed nature of the Red sea, its water content renewal is limited. It is estimated that it would take 200 years for the renewal of the entire water in the Red sea. (Gladstone, Facey \& Hariri, 2006; Hariri, Gladstone \& Facey, 2014). Dumping toxic waste products in any semi-enclosed oceanic space such as the Persian Gulf or the Red Sea constitutes a considerable stress condition towards its marine life (Table 1).

\section{Common microorganism isolates in the Persian Gulf and Gulf of Oman in relation to the} Red Sea

Due to the environmental stress conditions in marine life, many organisms pull through by releasing secondary metabolites which might be toxic and bioactive at the same time (Vaseghi et al., 2018). These bioactive compounds may be considered as an important source for drug discovery. Soft corals, seaweed and algae, sponges, bacteria, and fungi are some of the marine organisms that have been researched for potential bioactivity (Dobretsov et al., 2016). They have been reported to elaborate alkaloids, anthraquinones, ethers and many other chemical families that possess antioxidant, antimicrobial, anti-inflammatory, antitumor and cytotoxic activities (Lee et al., 2013a).

Fungi are more environment friendly to study than other marine corals and organisms. They are easily isolated and grown in the lab which makes it safer for the marine environment. The extreme conditions of marine life have caused fungi to become stress-resistant by forming many useful secondary metabolites (Alwakeel, 2017). These metabolites are said to have important biological activities including antimicrobial, anticancer, antioxidants and even antidiabetic, which is one of the reasons fungi are becoming more popular in marine drug discovery research (Hasan et al., 2015).

The Red Sea and Persian Gulf and Gulf of Oman are rich in marine fungi, and therefore, rich in bioactive compounds due to their high stress environments enhancing the synthesis and release of toxic and bioactive chemicals. Several common organisms have been found in both the Red Sea and Persian Gulf such as, Aspergillus sp., Penicillium sp., Talaromyces sp. and Trichoderma sp. (Nosratabadi et al., 2017).

Nonetheless, Aspergillus species have been found and extensively researched in the Red Sea marine environment. However, Aspergillus species isolated from the Persian Gulf such as, $A$.

flavus, A. niger, A. fumigatus and A. terreus are significantly under-researched compared to the same species isolated from the Red Sea. In addition, many other Aspergillus species were found in the Red Sea (A. sydowii, A. ochraceus, A. unguis, A. clavatus, A. versicolor, A. utus and A. caespitosus) but yet to be isolated and reported from the Persian Gulf (Alwakeel, 2017). This leads us to the following questions: 1) Are these fungi unable to survive the marine stress of the Persian Gulf rather than surviving the environmental stress of the Red Sea or simply not isolated yet? 2) Are the same Aspergillus species isolated from the Persian Gulf likely to synthesize the same portfolio of bioactive compounds like those isolated from the Red Sea?

Peer] reviewing PDF | (2021:02:58376:1:1:NEW 14 Jun 2021) 
220

221

222

223

224

225

226

227

228

229

230

231

232

233

234

235

236

237

238

239

240

241

242

243

244

245

246

247

248

249

250

251

252

253

254

255

256

257

258

Aspergillus is considered a terrestrial fungus which can survive in the marine environment in specific conditions. It has numerous species that produce multiple bioactive metabolites. Bioactive metabolites from $A$. fumigatus show potent broad spectrum antimicrobial (Shaaban et al., 2013). A. versicolor has plenty of bioactive compounds which were found to be antioxidant, antibacterial, fungicidal, and lipid lowering agents (Ahmed et al., 2017). A. unguis possesses a bioactive metabolite with $\alpha$-glucosidose inhibitory, antimicrobial and antioxidant effects (Abd El-Hady et al., 2015). Indole alkaloids isolated from A. ochraceus shows antitumor effects against several tumor types. A. utus also possesses cytotoxic metabolites against several cancer types (Lee et al., 2013b).

\section{Biological activities and chemical structures of some secondary metabolites isolated from} Aspergillus Spp.

The fungal flora, Aspergillus in specific, is understudied in the Persian Gulf. However, according to the available literature, $A$. flavus, . fumigatus, $A$. niger and $A$. terreus were found in the soil sediment of the Persian Gulf. It is worth mentioning that A. fumigatus, A. flavus, and A. niger account for more than 95\% of the Aspergillus species pathogens (Nosratabadi et al., 2017). Aspergillus flavus is a saprophytic soil type fungus which contaminates and infects seed crops. It is best known for aflatoxin secondary metabolite, which acts as a potent carcinogenic compound (Cary et al., 2018) and aspergillosis disease which affects immunocompromised patients (Amaike \& Keller, 2011; Cary et al., 2018). The aflatoxins are highly substituted difuranocoumarins fused with dihydrofurofuran moiety (Marchese et al., 2018). Different toxins belong to aflatoxins family such as Aflatoxin B1 (AFB1(1)) which is known to be the most harmful and Aflatoxin M1 (AFM1(2)) (Table 2), the hydroxylated metabolite of AFB1 (1), both are classified as human carcinogens through the activation of CYP450 (Marchese et al., 2018). Aspergillus fumigatus belongs to the filamentous fungi family that is present in the environment and can cause many diseases and life-threatening conditions in immunocompromised patients (Van De Veerdonk et al., 2017). Due to the stressful environmental conditions, A. fumigatus adapts via the production of several secondary metabolites and different mycotoxins such as, gliotoxin (4), fumagillin (5) and pseurotin A (6) (Table 3). Interestingly, A. fumigatus is reported to produce up to 226 secondary metabolites. Since the time of its discovery; studies focused on the biological activities of fumagillin such as its antitumor, antibacterial and antiparasitic effects. (Guruceaga et al., 2020).

Aspergillus niger is a human pathogenic filamentous ascomycete fungi which is known to have a vital economic role in the industrial scale fermentation for the production of citric acid (Baker, 2006). In addition, A. niger is known to produce ochratoxin A (7) and fumonisins (8-13) (Table 4). Fumonisins are toxic and carcinogenic metabolites, amongest Fumonisins B1 (FB1) (8), B2 (FB2) (9) and B3 (FB3) (10) are the most abundant in the fungal cultures (Baker, 2006; Tamura et al., 2014).

Aspergillus terreus is an important bio-processor fungus as it is useful in the production of many bioactive metabolites such as, itaconic acid (14) and metatartaric acid (15) lovastatin (16), 
259

260

261

262

263

264

265

266

267

268

269

270

271

272

273

274

275

276

277

278

279

280

281

282

283

284

285

286

287

288

289

290

291

292

293

294

295

\section{6}

297

298

territrem B (17) and terreulactone (18) (Table 5). In addition, there are many other mycotoxins secondary metabolites of A. terreus such as, patulin (19) (Table 5), ochratoxins A (7) (Table 4), citrinin (20), emodin (21) and sulochrin (22) (Table 5) (Varga et al., 2005). Amongst the above, lovastatin (16) is the first to be discovered (HMG)-CoA reductase inhibitor with potent antihyperlipidemic effects. Another notable metabolite of A. terreus is Terrein (23) (Table 5) that was isolated for the first time in 1935 and attracted a lot of attention due to its versatile bioactivities including inhibition of plant growth, anti-microbial, anti-proliferative, and antioxidative activities (Zhang et al., 2018). Yet, the chemical structures and accordingly the biological activities of $A$. terreus isolated secondary metabolites are non-surprisingly very versatile (Boruta \& Bizukojc, 2017).

Asperigllus versicolour is a marine endophytic fungus that is isolated from the inner tissue of the green alga called Halimeda opuntia found in the Red Sea (Finefield et al., 2011). A. versicolour contain diverse set of secondary metabolites such as Diketopiperazine (DKP) (24), Fellutamides F (25), sterigmatocystin (26), Dihydrosterigmatocystin (27), Cottelosines A and B (33 and 34) several anthraquinones (28-32), isorhodoptilometrin-1- methyl ether (35), siderin (37), emodin (22) evariquinone (36), arugosin-C (38), and variculanol (39) (Table 6), sesquiterpenoid nitrobenzoyl esters, chormone derivatives, meroterprnoid and quinazolinone alkaloids which are reported to possess anti-cancer, antibacterial, insecticidal, fungicidal, antioxidant, lipid lowering properties and HCV protease inhibitory action (Lee et al., 2010, 2011; Zhuang et al., 2011; Hawas, El-Beih \& El-Halawany, 2012; Ahmed et al., 2017)

Aspergillus ochraceus is a marine mitosporic fungus from the trichocomaceae family which was isolated from brown mold/clay of the Red Sea sediments. It can also be found in dried food, such as; dried beans, nuts dried fish and oilseeds (de W Blackburn, 2006). Several secondary metabolites were isolated from $A$. ochraceus such as the phenylated indole alkaloids Stephacidines $(40,41)$ (Table 7 ) which showed potent antitumor activity against several tumor types (Artman, Grubbs \& Williams, 2007; Finefield et al., 2011; Lee et al., 2013b). Yet, Stephacidine B (41) is the most complex isolated alkaloids found until the beginning of the twenty first century (Qian-Cutrone et al., 2002).

\section{Conclusion}

The marine environmental stress conditions indue many faunae and symbiont microorganisms to synthesize and release secondary metabolites of unique structure and interesting biological 
299

300

301

302

303

304

305

306

307

308

309

310

311

312

313

314

315

316

317

318

319

320

321

322

323

324

325

326

327

328

329

330

331

332

333

334

335

336

337

338 activities. These bioactive compounds can serve as an important source for drug discovery. The Persian Gulf/Gulf of Oman have a significantly harsher environment when compared to The Red Sea due to fluctuating temperatures between summer and winter which leads to high evaporation rates. Moreover, high salinity also contributes to the harsh environment leading microorganisms to live close to their limits of environmental tolerance. The Red Sea marine symbionts derived bioactive metabolites are very well studied while very much untapped in the Persian Gulf/Gulf of Oman. In the current perspective, and due to similar fungal species isolated from both environments, we are expecting interesting and unique secondary metabolites to be found and isolated from the marine life of the Persian Gulf/Gulf of Oman. The authors believe that using the Red Sea as a reference to target similar microorganisms that have elaborated bioactive metabolites is worthwhile. With the extreme environmental conditions in the Persian Gulf and Gulf of Oman, it is likely that marine research will lead to the isolation and identification of novel metabolites of medicinal value.

\section{References}

1. Patridge E, Gareiss P, Kinch MS, Hoyer D. An analysis of FDA-approved drugs: natural products and their derivatives. Drug Discov Today. 2016;21:204-7.

2. Newman DJ, Cragg GM. Natural products as sources of new drugs over the 30 years from 1981 to 2010. J Nat Prod. 2012;75:311-35.

3. Seibel BA, Drazen JC. The rate of metabolism in marine animals: environmental constraints, ecological demands and energetic opportunities. Philos Trans R Soc B Biol Sci. 2007;362:2061-78.

4. El-Hossary, EM, Abdel-Halim, M, Ibrahim, ES, Pimentel-Elardo, SM, Nodwell, JR, Handoussa, $\mathrm{H}$, Abdelwahab, MF, Holzgrabe, $U$ and Abdelmohsen, UR. Natural Products Repertoire of the Red Sea. Mar Drugs. 2020;18:457.

5. Naser HA. Marine ecosystem diversity in the Persian Gulf: threats and conservation. Biodiversity-The Dyn Balanc Planet. 2014;:297-328.

6. Ellis, JI, Jamil, T, Anlauf, H, Coker, DJ, Curdia, J, Hewitt, J, Jones, BH, Krokos, G, Kürten, B, Hariprasad, D and Roth, F. Glob Chang Biol. 2019;25:4131-46.

7. Paparella F, Xu C, Vaughan GO, Burt JA. Coral bleaching in the Persian/Persian Gulf is modulated by summer winds. Front Mar Sci. 2019;6:205.

8. Gladstone W, Facey R, Hariri K. State of the Marine Environment: Report for the Red Sea and Gulf of Aden. Reg Organ Conserv Environ Red Sea Gulf Aden (PERSGA), Jeddah. 2006. 9. Hariri K, Gladstone W, Facey CR. State of the marine environment-Report for the Red Sea and Gulf of Aden: 2006. 2014. 
339

340

341

342

343

344

345

346

347

348

349

350

351

352

353

354

355

356

357

358

359

360

361

362

363

364

365

366

367

368

369

370

371

372

373

374

375

376

377

378

379

380

381

382

10. Ben-Hasan A, Christensen V. Vulnerability of the marine ecosystem to climate change impacts in the Persian Gulf-an urgent need for more research. Glob Ecol Conserv. 2019;17:e00556.

11. Sheppard C. World Seas: An Environmental Evaluation: Volume III: Ecological Issues and Environmental Impacts. Academic Press; 2018.

12. Al Muftah A, Selwood Al, Foss AJ, Al-Jabri HMSJ, Potts M, Yilmaz M. Algal toxins and producers in the marine waters of Qatar, Persian Gulf. Toxicon. 2016;122:54-66.

13. Sale, PF, Feary, DA, Burt, JA, Bauman, AG, Cavalcante, GH, Drouillard, KG, Kjerfve, B, Marquis, E, Trick, CG, Usseglio, $P$ and Van Lavieren, $H$. The growing need for sustainable ecological management of marine communities of the Persian Gulf. Ambio. 2011;40:4-17. 14. Issa N, Vempatti S. Oil spills in the Persian Gulf: A case study and environmental review. Environ Nat Resour Res. 2018;8.

15. Eidnes IM, Batalden BM, Sydnes AK. Maritime Security and Threat Assessments.

TransNav, Int J Mar Navig Saf od Sea Transp. 2019;13.

16. Vaseghi G, Hajakbari F, Sajjadi S, Dana N, Ghasemi A, Yegdaneh A. Cytotoxic Screening of Marine Organisms from Persian Gulf. Adv Biomed Res. 2018;7.

17. Dobretsov S, Tamimi Y, Al-Kindi MA, Burney I. Screening for anti-cancer compounds in marine organisms in Oman. Sultan Qaboos Univ Med J. 2016;16:e168.

18. Lee, JC, Hou, MF, Huang, HW, Chang, FR, Yeh, CC, Tang, JY and Chang, HW. Marine algal natural products with anti-oxidative, anti-inflammatory, and anti-cancer properties. Cancer Cell Int. 2013;13:1-7.

19. Alwakeel SS. Molecular identification of fungi isolated from coastal regions of Red Sea, Jeddah, Saudi Arabia. J Assoc Arab Univ Basic Appl Sci. 2017;24:115-9.

20. Hasan S, Ansari Ml, Ahmad A, Mishra M. Major bioactive metabolites from marine fungi: A Review. Bioinformation. 2015;11:176.

21. Nosratabadi, M., Kordbacheh, P., Kachuei, R., Safara, M., Rezaie, S., Afshari, M.A. and Jafari, H.. Isolation and identification of non-pathogenic and pathogenic fungi from the soil of Greater Tunb, Abu-Musa and Sirri Islands, Persian Gulf, Iran. J Appl Biotechnol Reports. 2017;4:713-8.

22. Shaaban M, Nasr H, Hassan AZ, Asker MS. Bioactive secondary metabolities from endophytic Aspergillus fumigatus: Structural elucidation and bioactivity studies. Rev Latinoam química. 2013;41:50-60.

23. Ahmed EF, Rateb ME, Abou El-Kassem LT, Hawas UW. Anti-HCV protease of diketopiperazines produced by the Red Sea sponge-associated fungus Aspergillus versicolor. Appl Biochem Microbiol. 2017;53:101-6.

24. Abd El-Hady FK, Abdel-Aziz MS, Shaker KH, El-Shahid ZA, Ibrahim LS. Antioxidant,

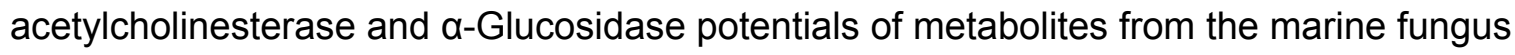
Aspergillus unguis RSPG_204 associated with the sponge (Agelas sp.). Int J Pharm Sci Rev Res. 2015;30:272-8.

25. Lee YM, Kim MJ, Li H, Zhang P, Bao B, Lee KJ, Jung JH. Marine-derived Aspergillus species as a source of bioactive secondary metabolites. Mar Biotechnol. 2013;15:499-519. 26. Cary JW, Gilbert MK, Lebar MD, Majumdar R, Calvo AM. Aspergillus flavus secondary metabolites: More than just aflatoxins. Food Saf. 2018;6:7-32.

27. Amaike S, Keller NP. Aspergillus flavus. Annu Rev Phytopathol. 2011;49:107-33.

Peer) reviewing PDF | (2021:02:58376:1:1:NEW 14 Jun 2021) 
383

384

385

386

387

388

389

390

391

392

393

394

395

396

397

398

399

400

401

402

403

404

405

406

407

408

409

410

411

412

413

414

415

416

417

418

419

420

421

422

28. Marchese S, Polo A, Ariano A, Velotto S, Costantini S, Severino L. Aflatoxin B1 and M1: Biological properties and their involvement in cancer development. Toxins (Basel). 2018;10:214. 29. Van De Veerdonk FL, Gresnigt MS, Romani L, Netea MG, Latge J-P. Aspergillus fumigatus morphology and dynamic host interactions. Nat Rev Microbiol. 2017;15:661.

30. Guruceaga X, Perez-Cuesta U, Abad-Diaz de Cerio A, Gonzalez O, Alonso RM, Hernando FL, Ramirez-Garcia A, Rementeria A.. Fumagillin, a mycotoxin of Aspergillus fumigatus: biosynthesis, biological activities, detection, and applications. Toxins (Basel). 2020;12:7. 31. Baker SE. Aspergillus niger genomics: past, present and into the future. Med Mycol. 2006;44 Supplement_1:S17-21.

32. Tamura M, Mochizuki N, Nagatomi Y, Toriba A, Hayakawa K. Characterization of fumonisin A-series by high-resolution liquid chromatography-orbitrap mass spectrometry. Toxins (Basel). 2014;6:2580-93.

33. Varga J, Tóth B, Kocsubé S, Farkas B, Szakács G, Téren J, Kozakiewicz Z. Evolutionary relationships among Aspergillus terreus isolates and their relatives. Antonie Van Leeuwenhoek. 2005;88:141-50.

34. Zhang X, Wu Z, Lai Y, Li D, Wang J, Luo Z, Xue Y, Zhu H, Chen C, Zhang Y. ( \pm )Terreinlactone $A$, a Pair of 3-Substituted $\delta$-Lactone Enantiomers Derived from Terrein from the Fungus Aspergillus terreus. Chem Pharm Bull. 2018;66:764-7.

35. Boruta T, Bizukojc M. Production of lovastatin and itaconic acid by Aspergillus terreus: a comparative perspective. World J Microbiol Biotechnol. 2017;33:34.

36. Finefield JM, Greshock TJ, Sherman DH, Tsukamoto S, Williams RM. Notoamide E: biosynthetic incorporation into notoamides $C$ and $D$ in cultures of Aspergillus versicolor NRRL 35600. Tetrahedron Lett. 2011;52:1987-9.

37. Lee Y-M, Li J, Zhang P, Hong J-K, Lee C-O, Jung J-H. A cytotoxic fellutamide analogue from the sponge-derived fungus Aspergillus versicolor. Bull Korean Chem Soc. 2011;32:381720.

38. Lee YM, Li H, Hong J, Cho HY, Bae KS, Kim MA, Kim DK, Jung JH. Bioactive metabolites from the sponge-derived fungus Aspergillus versicolor. Arch Pharm Res. 2010;33:231-5. 39. Zhuang Y, Teng X, Wang Y, Liu P, Wang H, Li J, Li G, Zhu W. Cyclopeptides and polyketides from coral-associated fungus, Aspergillus versicolor LCJ-5-4. Tetrahedron. 2011;67:7085-9.

40. Hawas UW, El-Beih AA, El-Halawany AM. Bioactive anthraquinones from endophytic fungus Aspergillus versicolor isolated from red sea algae. Arch Pharm Res. 2012;35:1749-56. 41. de W Blackburn C. Food spoilage microorganisms. Woodhead Publishing; 2006. 42. Artman GD, Grubbs AW, Williams RM. Concise, asymmetric, stereocontrolled total synthesis of stephacidins A, B and notoamide B. J Am Chem Soc. 2007;129:6336-42. 43. Zhuang Y, Teng X, Wang Y, Liu P, Wang H, Li J, Li G, Zhu W. Stephacidin A and B: two structurally novel, selective inhibitors of the testosterone-dependent prostate LNCaP cells. J Am Chem Soc. 2002;124:14556-7.

Peer) reviewing PDF | (2021:02:58376:1:1:NEW 14 Jun 2021) 


\section{Table $\mathbf{1}$ (on next page)}

Table 1

Comparative summary on general aspects of the Red Sea and Persian Gulf and Gulf of Oman 
Table 1. Comparative summary on general aspects of the Red Sea and Persian Gulf and Gulf of Oman

\begin{tabular}{|c|c|c|}
\hline Aspect & The Red Sea & The Persian Gulf \& Gulf of Oman \\
\hline Temperature & $\begin{array}{l}\text { - Minimum sea-surface temperature: } \\
18^{\circ} \mathrm{C} \\
\text { - Maximum sea-surface temperature: } \\
26.6^{\circ} \mathrm{C}\end{array}$ & $\begin{array}{l}\text { - Sea temperature: } 15^{\circ} \mathrm{C} \text { to } 36^{\circ} \mathrm{C} \text { during the winter and } \\
\text { summer seasons } \\
\text { - Average sea-surface temperature: } 37.7^{\circ} \mathrm{C}\end{array}$ \\
\hline \multirow[t]{2}{*}{ Salinity } & $\begin{array}{l}\text { - The evaporation rate in the Red sea } \\
\text { reaches } 1 \text { to } 2 \text { meters per year }\end{array}$ & $\begin{array}{l}\text { - The annual input of freshwater into the Gulf averages } \\
110 \mathrm{~km} 3 \text { per year } \\
\text { - The annual evaporation rates ranges between } 360 \text { to } \\
1250 \mathrm{~km} 3 \text { per year }\end{array}$ \\
\hline & $\begin{array}{l}\text { - There is no significant difference in th } \\
\text { areas in the Persian Gulf where the sali }\end{array}$ & $\begin{array}{l}\text { linity of the Persian Gulf and the Red sea except for some } \\
\text { exceeds 40ppt. }\end{array}$ \\
\hline \multirow[t]{2}{*}{$\begin{array}{l}\text { Shipping } \\
\text { Traffic }\end{array}$} & $\begin{array}{l}\text { - Over 20,000 ships (oil and non-oil } \\
\text { products) crosses through Bab el } \\
\text { Mandeb strait annually }\end{array}$ & $\begin{array}{l}\text { - The oil transportation accounts for 53,000 ships passing } \\
\text { through the Hormuz into the Gulf annually }\end{array}$ \\
\hline & \multicolumn{2}{|c|}{$\begin{array}{l}\text { - Shipping traffic in the Persian Gulf is much higher compared to the Red sea. } \\
\text { - There is no official data available on the overall shipping traffic of the Persian Gulf as just the oil } \\
\text { shipment in the Persian Gulf is two times more than the overall shipping traffic in the Red sea. }\end{array}$} \\
\hline Oil Spill & \multicolumn{2}{|c|}{$\begin{array}{l}\text { - The Persian Gulf has witnessed significant oil spill incidents in the world } \\
\text { - The number of oil spills in the Red sea has not been recorded } \\
\text { - It is evident that the number of oil spills in the Persian Gulf is way higher when comparing it to the Red } \\
\text { sea }\end{array}$} \\
\hline $\begin{array}{l}\text { Industrial } \\
\text { Effluents }\end{array}$ & $\begin{array}{l}\text { - An estimate of } 200 \text { years for the } \\
\text { renewal of the entire water }\end{array}$ & - The flushing time of the seawater is between 3 to 5 years \\
\hline
\end{tabular}




\section{Table 2 (on next page)}

Table 2

Example of some bioactive metabolites derived from the marine fungi Aspergillus flavus 
1 Table 2. Example of some bioactive metabolites derived from the marine fungi Aspergillus 2 flavus

Aflatoxin $\mathrm{B}$ (AFB1) (1)

3

4

5 


\section{Table 3(on next page)}

Table 3

Example of some bioactive metabolites derived from the marine fungi Aspergillus fumigatus 
1 Table 3. Example of some bioactive metabolites derived from the marine fungi Aspergillus 2 fumigatus.

3

Gliotoxin (4) Aspergillus fumigatus

4 


\section{Table 4 (on next page)}

Table 4

Example of some bioactive metabolites derived from the marine fungi Aspergillus niger 
1 Table 4. Example of some bioactive metabolites derived from the marine fungi Aspergillus niger.

2

\begin{tabular}{ll}
\hline Aspergillus niger \\
\hline
\end{tabular}

3

4 


\section{Table 5 (on next page)}

\section{Table 5}

Example of some bioactive metabolites derived from the marine fungi Aspergillus terreus 
1

2 Table 5. Example of some bioactive metabolites derived from the marine fungi Aspergillus terreus

(14)

3 
Table 6(on next page)

Table 6

Example of some bioactive metabolites derived from the marine fungi Aspergillus versicolor 
1 Table 6. Example of some bioactive metabolites derived from the marine fungi Aspergillus 2 versicolor

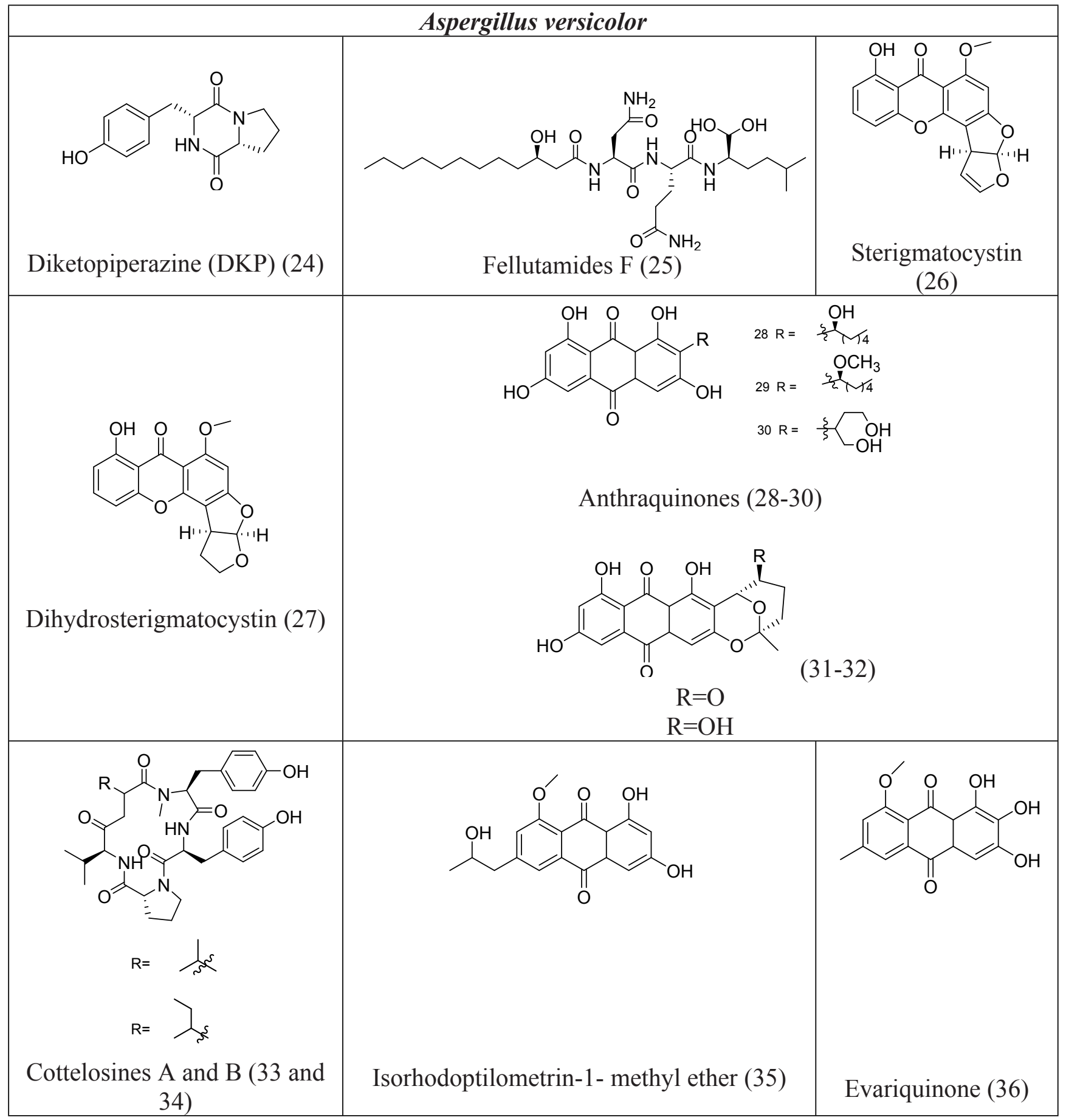




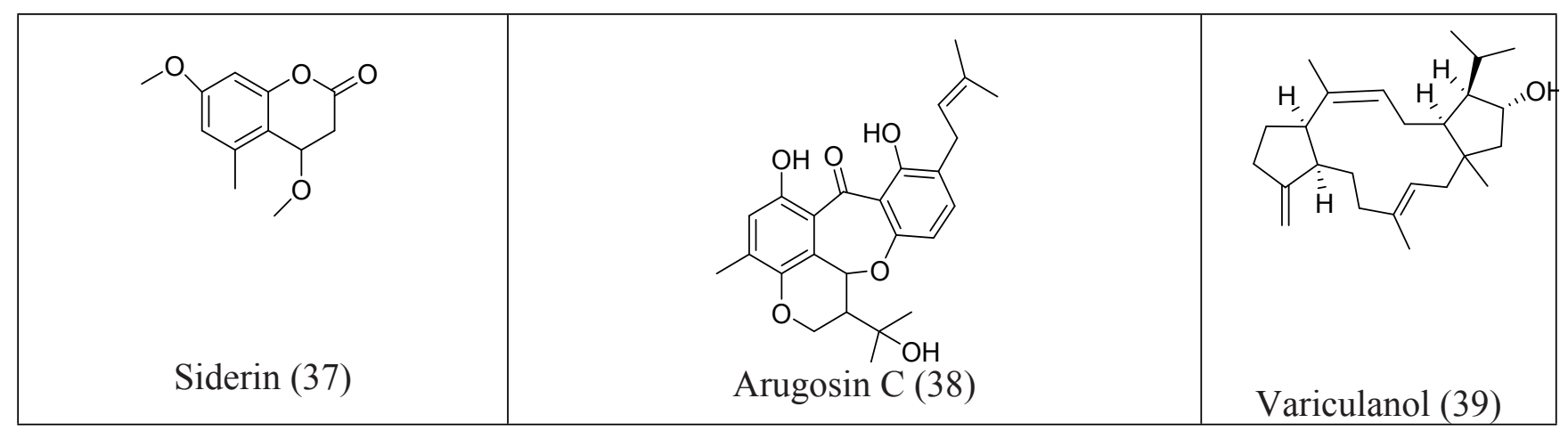

3 
Table 7 (on next page)

Table 7

Example of some bioactive metabolites derived from the marine fungi Aspergillus ochraceus 
1

2 Table 7. Example of some bioactive metabolites derived from the marine fungi Aspergillus 3 ochraceus

Stephacidines $\mathrm{A}(40)$

